\title{
Design Considerations for Permanent Magnet Direct Drive Generators for Wind Energy Applications
}

\author{
A. K. Jassal, H. Polinder, M. E. C. Damen, and K. Versteegh
}

\begin{abstract}
Permanent Magnet Direct Drive (PMDD) generators offer very high force density, high efficiency and low number of components. Due to these advantages, PMDD generators are getting popular in the wind energy industry especially for offshore application. Presence of permanent magnets gives magnetic field for free but there are many design considerations which must be taken into account for a good design. The design considerations presented in this paper are rotor eccentricity, short circuit current estimation, voltage reflection at generator terminals due to high frequency switching and forces during magnet assembly. Simplified analytical methods which give quick results have been developed and then simulations have been performed to validate the analytical models. FEMM 4.0 which is a Finite Element (FE) solver was used for validation of various magnetic force models. MATLAB ${ }^{\circledR}$ Simulink was used for short circuit and voltage reflection validation. It was deduced that the analytical methods give good estimation of these effects and can thus be included at an early design stage.
\end{abstract}

Index Terms-Design considerations, generator, permanent magnets, wind-energy.

\section{INTRODUCTION}

Wind energy is currently the most promising source of renewable energy. In order to further utilize the potential of wind, there is a drive to go offshore as the energy yield is higher there. One of the many possibilities is to use Permanent Magnet Direct Drive (PMDD) generators for offshore wind energy applications. These machines have very high force density, high efficiency, no gearbox and no field winding thereby reducing the number of components and improving reliability. In order to reach a good design in machines with Permanent Magnets (PMs), some well known challenges are cogging, magnet selection and protection, machine cooling etc. However, there are some lesser known problems which need attention during design stage of a PM machine. These problems form the basis of this paper and are introduced below:

1) Force due to permanent magnets near the iron parts. Manufacturing tolerances contribute to these inherent forces whereby assembly of such machines can be very challenging.

2) The converter switching at high frequencies with cables

Manuscript received April 20, 2012; revised May 28, 2012. This work was supported by XEMC-Darwind, Hilversum, Netherlands.

A. K. Jassal and H. Polinder are with Technical University of Delft, Mekelweg 4, 2628CD, Delft, Netherlands (e-mail: a.k.jassal@ tudelft.nl; h.polinder@tudelft.nl ).

M. E. C. Damen and K. Versteegh are with XEMC-Darwind B.V., Oude Enghweg 2, 1217 JC Hilversum, Netherlands (e-mail: m.damen@xemc-darwind.com; k.versteegh@xemc-darwind.com). in between generator and converter can lead to voltage reflection at generator terminals and hence overvoltage.

3) The magnets must not de-magnetize under influence of machine short circuit. Therefore proper selection of magnets and estimation of peak short circuit current is very important.

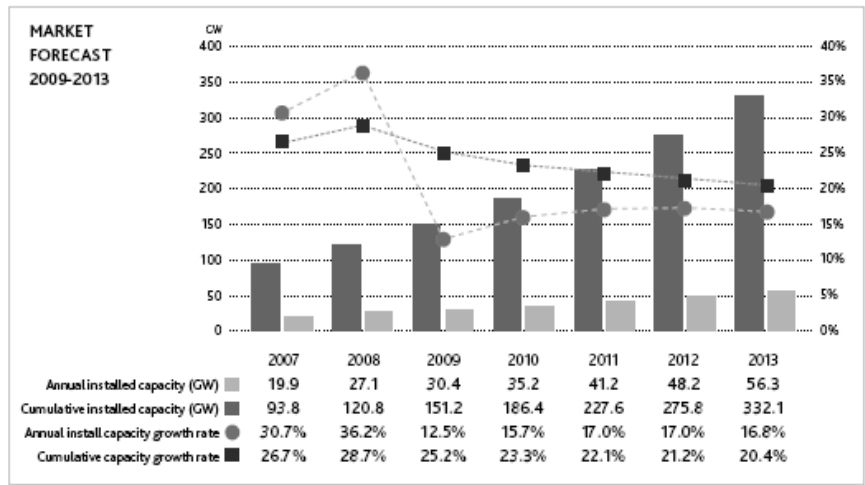

Fig. 1.Wind energy generation forecast [9]

These design considerations were used during design of a 2 MW PMDD generator with distributed windings. It has been concluded that these factors can be foreseen at an early design stage and analyzed for a PMDD machine design. The contribution of this research comes from the formulation of these simple methods and verification using Finite Element (FE) analysis and MATLAB-Simulink.

\section{Forces Due to Permanent Magnets}

Permanent Magnets with iron in their vicinity form an active system. Forces of attraction are inherent and have to be calculated to reach a good design. The following two cases are practical and important.

\section{A. Force on Rotor Due to Eccentricity}

In an ideal generator, the rotor is perfectly concentric with the stator bore. However due to large machine radius and very thin air gap, it is possible that the construction is not exactly concentric. An eccentric rotor can lead to bending moments on the shaft and shaft should be stiff enough to bear these moments.

Analytically, this force can be calculated using the following steps:

1) First by using Carter's factor [7], we can make the stator slot-less.

2) Then the stator bore surface is divided into equal segments, each having a particular area $A$ for every angle $\alpha$ of stator bore. It has been assumed that magnets cover the whole pole pitch for simplicity.

3) With a given eccentricity, we can find a change in air gap 
as a function of any position on stator bore. This change in air gap can simply be approximated as $e \cos (\alpha)$ because the air gap is much smaller as compared to the radius of stator bore. Thus,

$$
\Delta g=e \cos (\alpha)
$$

Here $\Delta g$ is the change in air gap

$e$ is eccentricity of rotor;

$\alpha$ is the angle along stator bore

4) Using Ampere's law the magnitude of flux density (for each area element $A$ ) in the air gap is estimated. This is a standard calculation and can be referred from [3], [4].

5) To calculate the force exerted by each area element, the following equation has been used

$$
F(\alpha)=\frac{\left(\hat{B}_{g}(\alpha)\right)^{2}}{2 \mu_{0}}
$$

Here, $F(\alpha)$ is the force of attraction (function of $\alpha$ )

$$
\begin{aligned}
& \hat{B}_{g} \text { is the peak of fundamental flux density } \\
& \mu_{0} \text { is the permeability of free space }
\end{aligned}
$$

6) This results in a distribution of these attraction forces in one half of machine.

7) The other half of the machine is treated similarly.

8) Then net force distribution is the difference of these two force distributions.

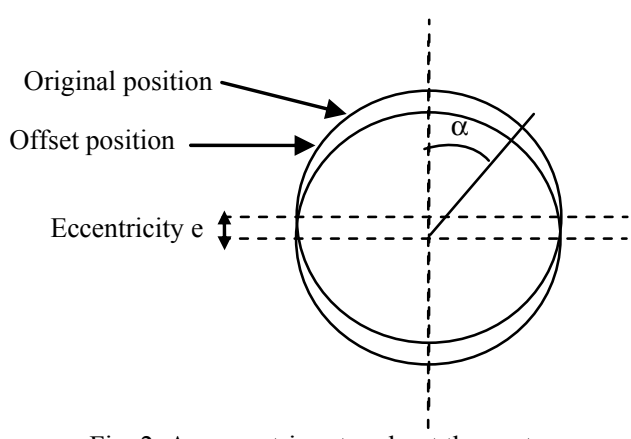

Fig. 2. An eccentric rotor about the centre

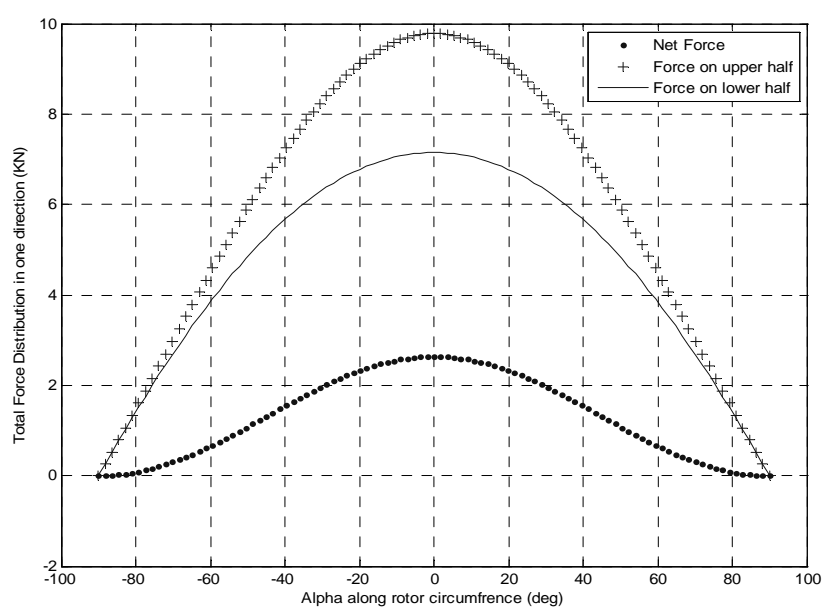

Fig. 3. Distribution of net attraction force

Further, to validate the model, FEMM 4.0 which is free Finite Element (FE) software from Foster Miller [10] was used to model the machine in FE.
The solver for this software is good for solving static time-harmonic problems. FEMM 4.0 software can't take into account the actual motion in real time.

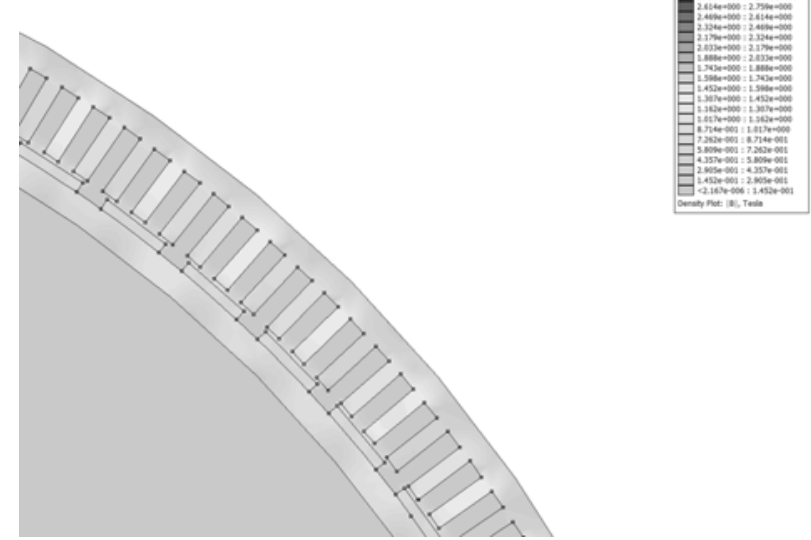

Fig. 4. Machine geometry used for calculation of attraction force

TABLE I: COMPARISON OF ANALYTICAL AND FE RESULTS

\begin{tabular}{|c|c|c|}
\hline \multirow{2}{*}{ Eccentricity $(\mathrm{mm})$} & FE calculation & Analytic calculation \\
\cline { 2 - 3 } & Force $(\mathrm{N})$ & Force $(\mathrm{N})$ \\
\hline 1 & 69140 & 68716 \\
\hline 2 & 78127 & 75762 \\
\hline 3 & 87530 & 83950 \\
\hline
\end{tabular}

The difference between FE and analytical calculation is because of the assumption that there are no slots in the machine and because effective air gap becomes large.

\section{B. Force on Magnet during Assembly on Rotor}

When a magnet is mounted on to the rotor which is placed inside the stator bore, it experiences a pull into the stator in the direction of insertion. It is because flux tries to flow through Iron part of the stator as it has lower reluctance than air. Estimation of this force helps in magnet protection.

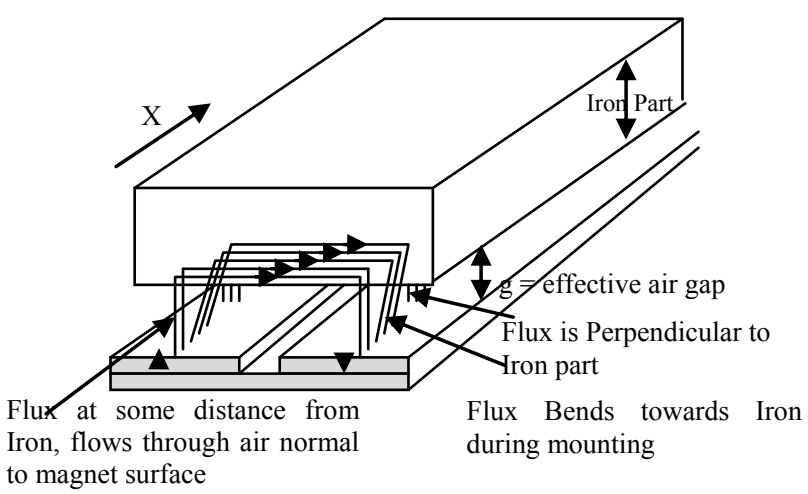

Fig. 5. Force during magnet assembly

In order to estimate this force, certain assumptions have been made:

a) There is no leakage or fringing of flux.

b) Iron part of the stator doesn't saturate.

The procedure to calculate this force is explained below:

1) Each PM can be modeled as a coil carrying some current such that mmf of coil $=\mathrm{mmf}$ of the magnet assembly. This mmf can be calculated using ampere circuital law along the flux path chosen.

2) We can express Inductance $L$ of the hypothetical coil as 
a function of reluctance using

$$
L=\frac{N^{2}}{R}
$$

Here, $N$ is the number of turns of the coil.

$R$ is the reluctance of the flux path

3) Reluctance is again a function of position of magnet with respect to stator iron.

4) A force tries to maximize Inductance whereby the magnet is pulled into the stator where reluctance is minimal.

5) This Force $F$ can be calculated as

$$
F=\frac{I^{2}}{2} \frac{d}{d x}(L(x))
$$

$I$ is the current calculated for desired mmf of PM

The unknown part in this whole exercise is to find out the reluctance by appropriately choosing the flux path. Consequently, we need to know the distance where magnet feels the influence of the iron part. In analytical calculations, as a rough guess, this was assumed to be equivalent to the effective air gap. As a check, the machine geometry was modeled with FEMM 4.0 to find out this distance. It was found to be about 1.25 times the effective air gap.

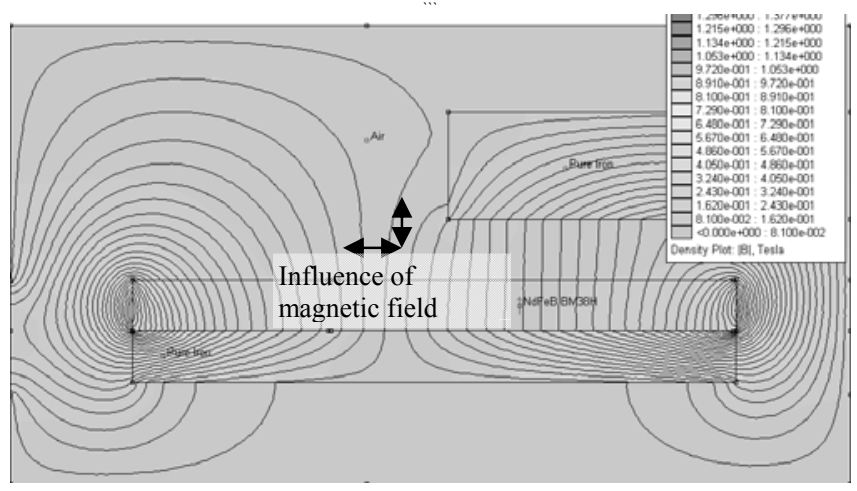

Fig. 6. Flux bending caused due to presence of iron

This force remains almost constant if we assume only one degree of freedom, along direction of insertion. It is so because active pull is provided by the flux which bends towards Iron and this amount of flux remains almost constant while magnet is being mounted. This force for the machine under consideration was found to be about $2.5 \mathrm{kN}$.

\section{Voltage Transients Due to Switching OF CONVERTER}

Due to switching action of the converter i.e. high rate of change of voltage $(\mathrm{du} / \mathrm{dt})$, overvoltage can be observed at generator terminals [8]. The simplified system consists of a generator, connected with cables to a voltage source which has a certain rate of rise of voltage or du/dt. The cable impedance is represented by a ' $\mathrm{T}$ ' equivalent circuit. The model has been made in Simulink. The schematic below shows the layout of the system.

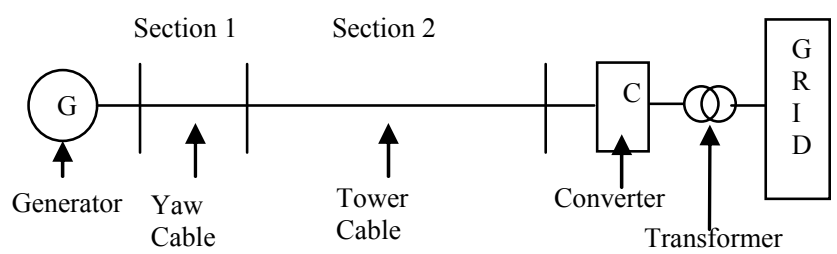

Fig. 7. Turbine system layout

The cables have been modeled as a distributed ' $\mathrm{T}$ ' equivalent circuit. The number of elements considered is four, connected next to each other. In theory, the longer the cable (or in general the transmission line) the higher is the number of equivalent networks required to achieve accurate results.

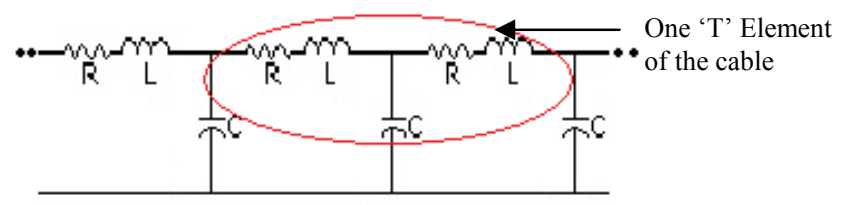

Fig. 8. T-equivalent model of cable

The system has been modeled with a controlled voltage source generating a voltage with a high rate of rise $(\mathrm{du} / \mathrm{dt})$. Switching on time $\left(\mathrm{T}_{\text {on }}\right)$ has been taken as $200 \mathrm{~ns}$ for the simulation. The switching off time $\left(\mathrm{T}_{\text {off }}\right)$ was assumed $800 \mathrm{~ns}$. The voltage level to be switched is $1000 \mathrm{~V}$. Thus we can define rate of rise and rate of decay of voltage or $\mathrm{du} / \mathrm{dt}$ of the switching pulse as in (5).

$$
\begin{aligned}
& \left(\frac{d u}{d t}\right)_{\text {on }}=\frac{V}{T_{\text {on }}} \\
& \left(\frac{d u}{d t}\right)_{\text {off }}=\frac{V}{T_{\text {off }}}
\end{aligned}
$$

Further, $T_{\text {on }}$ is smaller than $T_{\text {off }}$ while voltage to be handled is the same. This means that we can expect higher $\mathrm{du} / \mathrm{dt}$ during switching on of the device.

If we put the values in (5), we can find the input du/dt value to the system as:

$$
\left(\frac{d u}{d t}\right)_{\text {on }}=\frac{1000}{200.10^{-9}}=5000 \mathrm{~V} / \mu \mathrm{s}
$$

In Simulink, this can be simulated by using a signal generator along with a rate limiter. The signal generator generates a square wave and rate limiter puts the $\mathrm{du} / \mathrm{dt}$ value on the signal.

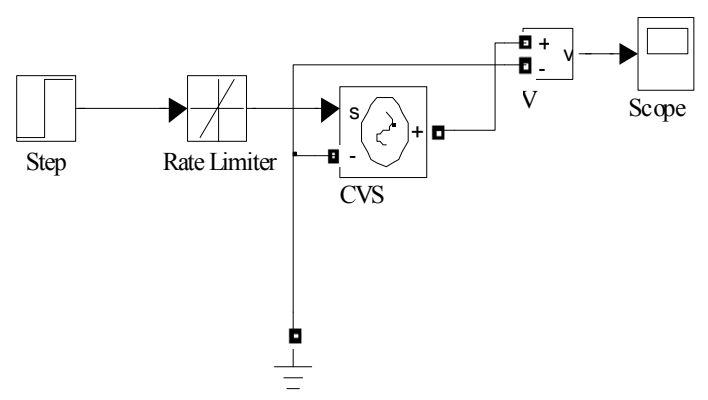

Fig. 9. Signal generator in MATLAB-simulink 


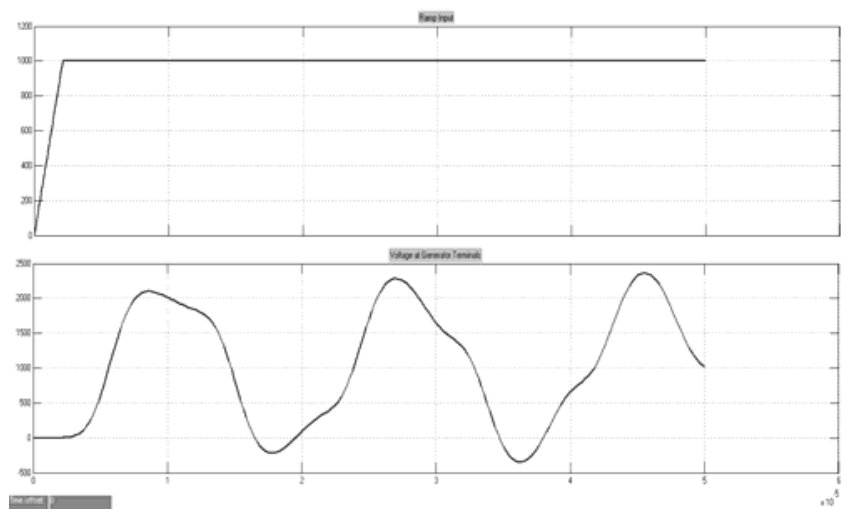

Fig. 10. Signal generator in MATLAB-simulink: upper figure is the input signal; lower figure is the voltage response

It can be seen that voltage at generator terminals is almost two times the switching voltage. It is desired to safeguard generator against these over-voltages. It might mean a filter to be used on generator side or selection of higher insulation voltage for generator and connecting cable.

\section{EFFECTS OF GENERATOR SHORT CIRCUIT}

The generator is crucial and an expensive component in a wind turbine. Two important consequences of generator short circuit worth analysis are short circuit current and torque along with de-magnetizing effects on PMs.

\section{A. Generator Short Circuit Current and Torque}

In an electrical machine during short circuit, current mostly flows through the leakage reactance. A good starting point for estimation is per unit analysis. The transient equivalent circuit of a machine under short circuit can be simplified as shown below [5],[6]:

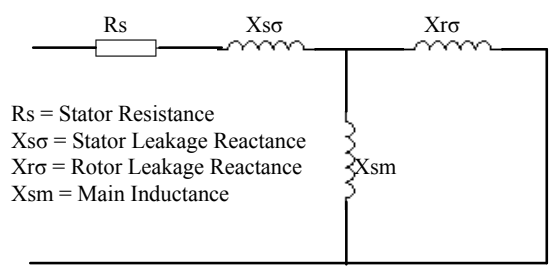

Fig. 11. Generator during short circuit: Per phase equivalent

Based on the equivalent circuit, we can get the first estimate of short circuit current using:

$$
\begin{aligned}
& V_{\text {base }}, P_{\text {base }}=\text { Per phase voltage and power (VA) } \\
& I_{\text {base }}=\frac{P_{\text {base }}}{V_{\text {base }}} ; Z_{\text {base }}=\frac{\left(V_{\text {base }}\right)^{2}}{P_{\text {base }}}
\end{aligned}
$$

Short circuit current to nominal current ratio is basically ratio of normal impedance to short circuit impedance. For validation, the inbuilt model of permanent magnet synchronous machine in MATLAB simulink was used after minor modifications. Full load balanced operation has been assumed for simulation. For the machine under consideration, the three phase short circuit current was found to be about 4.2 times the nominal current. However in order to effectively run this simulation, we need correct values of machine parameters [1] and [2].

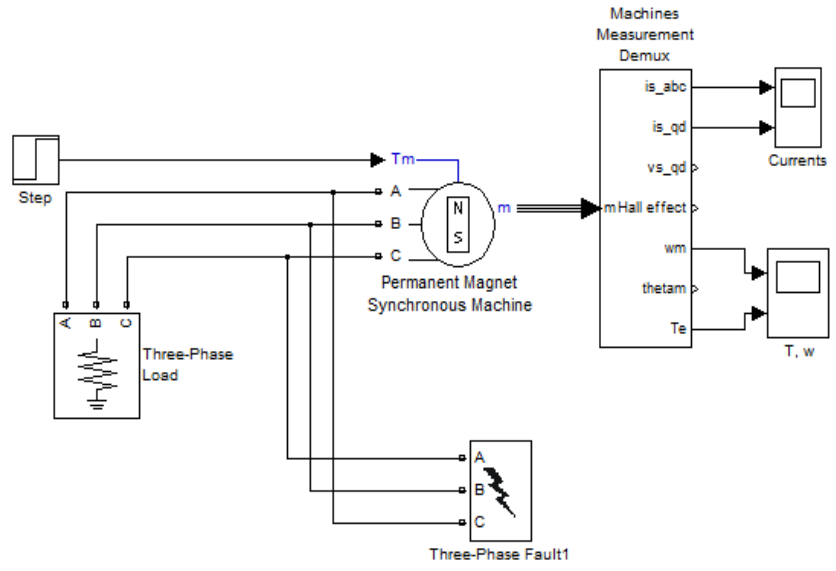

Fig. 12. Simulation model for generator short circuit

The simulation results are shown below:

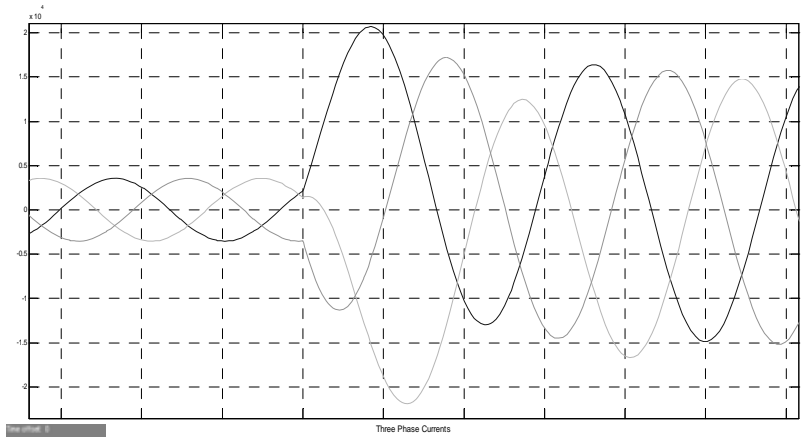

Fig. 13. Three phase currents during generator short circuit

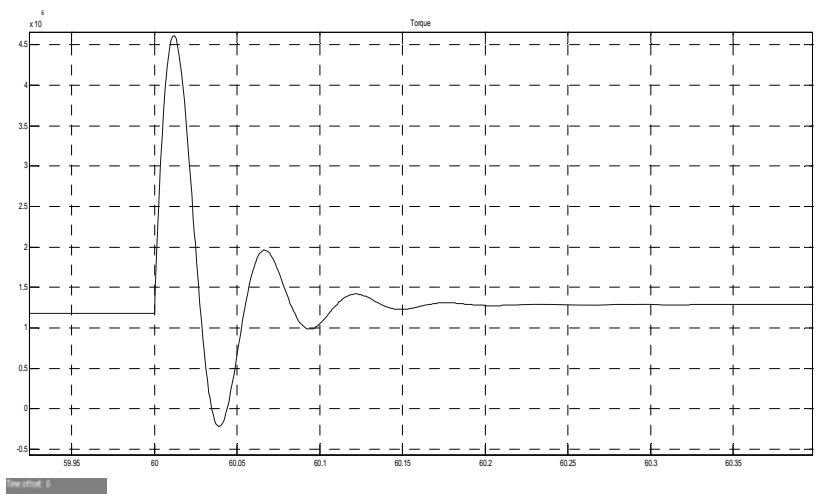

Fig. 14. Short circuit Torque

\section{B. Generator Short Circuit Demagnetizing mmf}

The demagnetizing mmf can be calculated using the following equation. This can be easily derived from Ampere's law:

$$
\hat{H}_{\text {short }}=-\left(\frac{N_{\text {slot }} \hat{I}_{\text {short }}+\frac{l_{m} B_{r}}{\mu_{0} \mu_{r m}}}{\frac{l_{m}}{\mu_{r m}}+g}\right)
$$

Here,

$\hat{H}_{\text {short }}$ is the peak value of short circuit mmf

$\hat{I}_{\text {short }}$ is the peak value of short circuit current

$N_{\text {slot }}$ is the number of conductors in the slot

$g$ is the air gap; $B_{r}$ is the remanent flux density 


\section{$\mu_{0}$ is the permeability of free space}

$l_{m}$ is the magnet thickness

Relative permeability of magnet has been assumed 1 in the analysis. The PM should have coercive force higher than this calculated demagnetizing mmf. A factor for temperature dependence of this coercive force can then be used in a manner similar to the resistance calculations.

\section{CONCLUSIONS}

The paper presents analytical methods regarding some design considerations for PMDD generators for wind energy applications. The conclusions can be summed up as:

1) The net force due to eccentricity of rotor in the air gap can be large but because it is a distributed force, the effect is not immense for small eccentricities of $1 \mathrm{~mm}$ or $2 \mathrm{~mm}$.

2) The inward pull of a magnet towards stator during magnet mounting on a pre-assembled rotor is not so large and is easily negotiable.

3) Due to high frequency voltage switching by converter, reflection of voltage can occur and the maximum it can reach is about twice the voltage level switched. The insulation of generator and the connecting cables should be able to withstand this recurring voltage stress.

4) Machine short circuit current is very crucial for magnet selection as de-magnetizing effect of short circuit current has to be taken into account.

5) The peak value of torque during short circuit can be a parameter to define shaft stiffness. This peak torque is proportional to peak short circuit current.

\section{REFERENCES}

[1] P. H. Mellor, F. B. Chaaban, K. J. Binns, "Estimation of parameters and performance of rare-earth permanent magnets motors avoiding measurement of load angle," IEE proceedings B, Electric power applications, vol. 138, Issue 6, Nov. 1991, pp.322-330.

[2] G. Dajaku and D. Gerling, "The correct analytical expression for self inductance of salient pole synchronous machines," Proc. IEEE European conference on power electronics and applications, 2-5 sept. 2007, pp.1-7.

[3] S. R. Holm, "Modelling and optimization of a permanent magnet machine in a flywheel," Ph.D. dissertation, pp. 62-66, Dept. Electrical Power Engineering, TU Delft, The Netherlands, 2003

[4] A. E. Fitzgerald, C. Kingsley and S. D. Umans, Electric machinery, $6^{\text {th }}$ edition, Mc. Graw Hill, pp.28-43 and 644-656.

[5] M. Kostenko and L. Piotrovsky, Electrical Machines part 2, 2nd edition, Peace Publishers Moscow, pp.354-355.
[6] P. C. Krause, O. Wasynczuk, and S. Sudhoff, Analysis of Electric Machinery, IEEE Press, pp. 276-278.

[7] A. K. Sawhney, A course in Electrical Machine Design, $5^{\text {th }}$ edition, Dhanpat Rai and Co. Publishers, pp.122-127 and 179-185.

[8] W. D. Stevenson Jr., Elements of Power System Analysis, $4^{\text {th }}$ edition, Mc. Graw Hill, pp.114-122.

[9] Global wind report 2008, Global Wind Energy Council, pp.12-15, http://www.gwec.net/fileadmin/documents/Global\%20Wind\%202008 $\% 20$ Report.pdf.

[10] FEMM 4.2 reference manual - Octave FEMM Chapter 2, pp.41-46, http://www.femm.info/Archives/doc/manual42.pdf

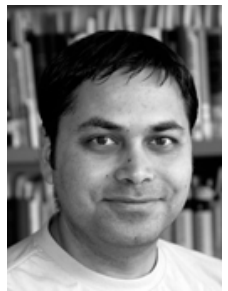

Anoop Jassal was born in India in 1983. He did his B.Engg. from PEC, Chandigarh, India in 2003. He finished his MSc in electrical power processing from TU Delft, Netherlands in 2008. He is currently working towards his $\mathrm{PhD}$ in the same department at $\mathrm{TU}$ Delft, Netherlands. He wroked as electrical engineer with Vardhman group of companies (VSGM) India from 2003-2005. He also worked part time for XEMC-Darwind during his $\mathrm{PhD}$ reasearch. His research interests include design and modeling of electrical machines, electrical power conversion systems and mechatronics.

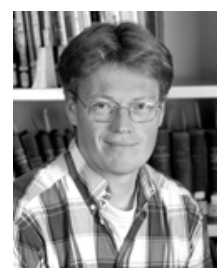

Henk Polinder was born in Nunspeet, the Netherlands, in 1968. He received the M.Sc. and Ph.D. degrees from Delft University of Technology in 1992 and 1998, respectively. From 1996 to 2003, he was an assistant professor and since 2003 he has been an associate professor in the Electrical Power Processing group of Delft University of Technology. He is mainly interested in design aspects of electrical machines for renewable energy (wind and waves) and mechatronic applications.

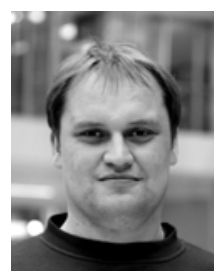

Michiel Damen was born in The Hague, the Netherlands, in 1976. He received his B.Sc. degree from the Technical Highschool Rijswijk in 1998 and the M.Sc. degree from Delft University of Technology in 2003. Since 2003, he has been working in the field of renewable energy especially wind energy. Currently he is employed by XEMC-Darwind, Hilversum as High Voltage Engineer. Electrical power aspects of renewable energy sources are his main interest. His specific interests are power converters, electromagnetic design of PM generators and grid interaction of wind turbines.

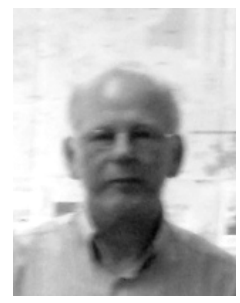

Kees Versteegh was born in The Netherlands in 1955 He did his bachelor study in Technical College Utrecht in 1976. Since then he has been working in the field of wind energy. He has been an independent consultant and then later worked for Netwind, Garrad Hassan and Harakosan. He was responsible for overall development of popular Zephyros concept of direct drive wind turbines. In 2006, he founded his own company in the name of VWEC in Hilversum, The Netherlands. At present he is working as chief technical officer (CTO) in XEMC-Darwind. His primary interests are permanent magnet direct drive wind turbines and new concepts for development of wind energy. 